\title{
TUGAS TATA KELOLA
}

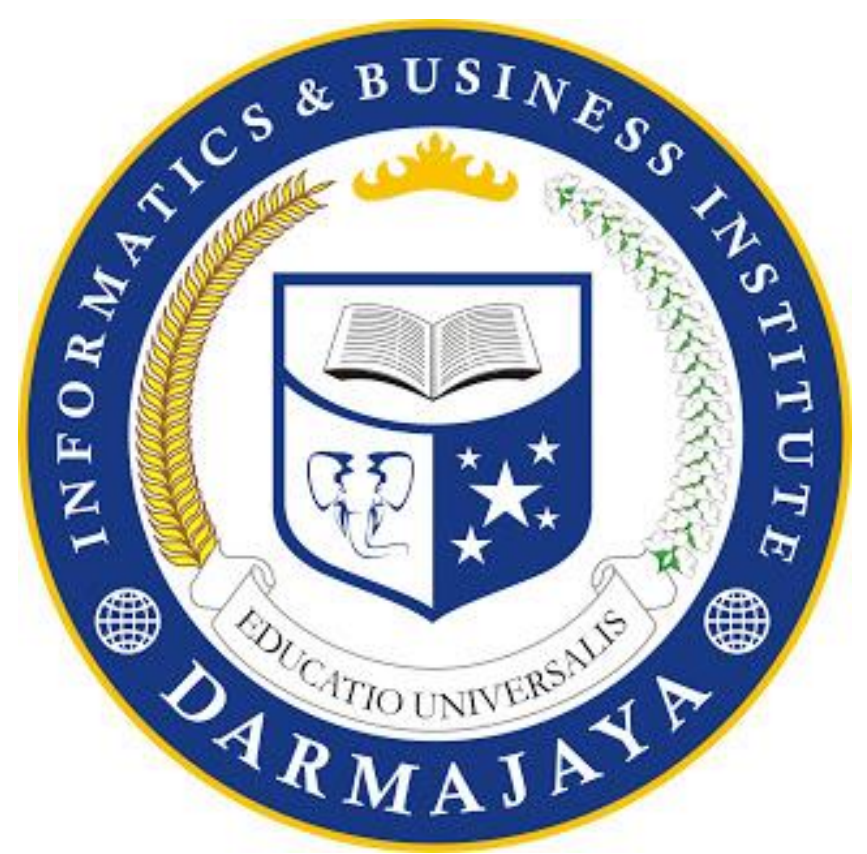

Disusun Oleh :

FEDRIKSEN

1511050035

INSTITUTE INFORMATICS \& BUSINESS DARMAJAYAI 2018/2019 


\title{
Audit Teknologi Informasi menggunakan Framework COBIT 5 Pada Domain DSS (Delivery, Service, and Support) (Studi Kasus : Universitas XYZ)
}

\author{
Abstraksi \\ Teknologi informasi (TI) merupakan suatu bagian yang sangat penting bagi \\ perusahaan atau lembaga dan merupakan suatu nilai investasi untuk menjadikan \\ perusahaan atau lembaga tersebut menjadi lebih baik. Perusahaan atau lembaga \\ menempatkan teknologi informasi sebagi suatu hal yang dapat mendukung \\ pencapaian rencana strategis perusahaan untuk mencapai sasaran visi, misi dan \\ tujuan perusahaan atau lembaga tersebut, begitu halnya dengan Universitas XYZ. \\ Teknologi Informasi yang diterapkan perlu diatur agar dapat dimanfaatkan dengan \\ baik. Untuk mengatur teknologi informasi itu sendiri memerlukan audit yang \\ bertujuan untuk mengevaluasi dan memastikan pemenuhannya ditinjau dari \\ pendekatan objektif dari suatu standar. Teknologi Informasi di Universitas XYZ \\ memerlukan audit untuk mengevaluasi, menilai kapabilitas, dan menyusun \\ rekomendasi terhadap teknologi informasi yang dipakai. Framework audit yang \\ digunakan adalah COBIT 5 domain DSS (Deliver, Service, dan Support) yang \\ fokus pada penilaian pengiriman dan layanan teknologi informasi serta \\ dukungannya termasuk pengelolaan masalah agar keberlanjutan layanan tetap \\ terjaga.
}




\section{Pendahuluan}

Saat ini Teknologi informasi (TI) menjadi suatu bagian yang sangat penting bagi perusahaan atau lembaga - lembaga yang bersekala enterpirse. Perusahaan atau lembaga menempatkan teknologi sebagi suatu hal yang dapat mendukung pencapaian rencana strategis perusahaan untuk mencapai sasaran visi, misi dan tujuan perusahaan atau lembaga tersebut. Perusahaan atau lembaga tersebut berupaya untuk menerapkan suatu sistem informasi yang dapat memenuhi kebutuhan perusahaan dalam mencapai tujuannya misalnya untuk meningkatkan kegiatan operasional kerja. Fungsi teknologi informasi tidak hanya untuk meningkatkan operasional kerja tetapi juga memberi nilai tambah dan keuntungan kompetitif Dengan berbagai keuntungan dan pentingnya Teknologi informasi, Perguruan Tinggi (PT) mengimplementasikan ke dalam proses operasionalnya. Perguruan tinggi dapat memanfaatkan Teknologi informasi untuk pelayanan administrasi, mendukung Kegiatan Belajar Mengajar (KBM), sebagai media berkomunikasi, dan membantu untuk pengambilan keputusan.

Dengan diimplimentasikan teknologi informasi yang baik pada PT maka akan meningkatkan kualitas layanan di PT tersebut. Universitas XYZ memiliki visi yaitu menjadi perguruan tinggi berkelas dunia ( $A$ World Class University) yang berperan aktif dalam pengembangan ilmu pengetahuan dan seni berbasis teknologi informasi. Universitas XYZ telah menerapkan penggunaan teknologi informasi sebagai penunjang dalam hal pelayanan akademik yang diperuntukan bagi seluruh civitas akademika . Audit teknologi informasi memiliki beberapa standar yang digunakan untuk peneletian. Contoh standar tersebut adalah ITIL dan COBIT 5. ITIL memiliki fokus pada layanan untuk pelanggan dan tidak memberikan proses penyelarasan strategi perusahaan terhadap strategi teknologi informasi yang dikembangkan . COBIT5 merupakan standar komprehensif yang membantu perusahaan dalam mencapai tujuan dan menghasilkan nilai melalui tata kelola dan manajemen teknologi informasi yang efektif. COBIT 5 menyediakan kerangka kerja IT Governance dan control objectives yang rinci bagi manajemen, pemilik proses bisnis, pemakai dan auditor, karena mengelola teknologi informasi secara holistic sehingga nilai yang diberikan oleh teknologi informasi dapat tercapai optimal dengan memperhatikan segala aspek tata kelola teknologi informasi mulai dari sisi people, skills, competencies, services, infrastructure, dan applications yang merupakan bagian dari enabler suatu tata kelola teknologi informasi . COBIT 5 menyediakan kerangka kerja yang lengkap. Terdapat 5 domain dan 37 proses pada COBIT 5 yang dapat digunakan untuk melakukan audit. Maka dari itu COBIT 5 dianggap sesuai dan dapat membantu dalam proses audit teknologi informasi karena mencakup semua elemen pada teknologi informasi yang dipakai.

Domain DSS dipilih karena dianggap sesuai dengan kondisi teknologi informasi yang ada pada Universitas XYZ saat ini. Dengan kondisi teknologi informasi di Universitas XYZ yang sedang berlangsung dan kebutuhan untuk mengirimkan layanan, melayani, dan mendukung layanan teknologi informasi, maka Domain DSS yang dianggap sesuai dengan hal tersebut. Domain lain seperti APO (Align, Plan, and Organize) akan dirasa sesuai diterapkan pada tata kelola teknologi informasi yang belum dijalankan atau akan dijalankan, domain BAI (Build, Acquire, and Implement) akan dirasa sesuai diterapkan pada unit khusus yang berperan sebagai pembangun (developer) atau memperbaiki tata kelola teknologi informasi yang sudah ada, domain MEA (Monitor, Evaluate, and Asses) akan dirasa sesuai diterapkan untuk kondisi yang telah dibangun dan berlangsung, dan 
pelaksanaan monitoring dilakukan oleh pihak internal, karena monitoring dengan audit memiliki intensitas dan jangka waktu yang berbeda

\section{Tinjauan Pustaka}

\section{Sistem}

Menurut Andri Kristanto (2008:1), "Sistem merupakan jaringan kerja dari prosedur - prosedur yang saling berhubungan, berkumpul bersama - sama untuk melakukan suatu kegiatan atau menyelesaikan suatu sasaran tertentu" [2].

Menurut Gordon B.Davis (1974;81), "Sistem dapat berupa abstrak atau fisis.

Sistem yang abstrak adalah susunan yang teratur dari gagasan-gagasan atau konsepsi- konsepsi yang saling bergantung"Azhar Susanto (2000:3), "Sistem adalah kumpulan /group dari sub sistem / bagian / komponen apapun baik phisik maupun non phisik yang saling berhubungan satu sama lain dan bekerja sama secara harmonis untuk mencapai satu tujuan tertentu"

Dari pengertian diatas, dapat disimpulkan bahwa sistem adalah kumpulan dari komponen - komponen yang saling berhubungan dan bergantung untuk mencapai suatu tujuan tertentu.

\section{Informasi}

Menurut Jogiyanto HM. (1999: 692), "Informasi dapat didefinisikan sebagai hasil dari pengolahan data dalam suatu bentuk yang lebih berguna dan lebih berarti bagi penerimanya yang menggambarkan suatu kejadian - kejadian (event) yang nyata (fact) yang digunakan untuk pengambilan keputusan” .

Menurut Anton M. Meliono. (1990: 331), "Informasi adalah data yang telah diproses untuk suatu tujuan tertentu. Tujuan tersebut adalah untuk menghasilkan sebuah keputusan".

Menurut Gordon B. Davis (1991: 28), "Informasi adalah data yang telah diolah menjadi sebuah bentuk yang berarti bagi penerimanya dan bermanfaat bagi pengambilan keputusan saat ini atau mendatang" . 
Dari pengertian diatas, dapat disimpulkan bahwa informasi adalah data yang telah diolah menjadi data yang berguna untuk suatu tujuan tertentu, yang dapat bermanfaat bagi pengambilan keputusan saat ini atau mendatang.

\section{Sistem Informasi}

Menurut Laudon, Kenneth, Jane (2007:42), "Sistem informasi adalah suatu sistem di dalam suatu organisasi yang mempertemukan kebutuhan pengolahan transaksi harian, mendukung operasi, bersifat manajerial dan kegiatan strategi dari suatu organisasi dan menyediakan pihak luar tertentu dengan laporan-laporan yang diperlukan”.

Menurut Budi Sutedjo Dharma Oetomo (2006: 36), "Sistem Informasi adalah kumpulan elemen yang saling berhubungan satu sama lain untuk membentuk suatu kesatuan untuk mengintegrasi data, memproses dan menyimpan serta mendistribusikan informasi tersebut Menurut Gondodiyoto (2007), "Sistem informasi dapat didefinisikan sebagai kumpulan elemen - elemen atau sumber daya dan jaringan prosedur yang saling berkaitan secara terpadu, terintegrasi dalam suatu hubungan hierarki tertentu, dan bertujuan mengolah data menjadi informasi”.

Menurut O'Brien (2005, P5), "Sistem informasi adalah suatu kombinasi terartur apapun dari people (orang), hardware (perangkat keras), software (piranti lunak), computer networks and data communications (jaringan komunikasi), dan database (basis data) yang mengumpulkan, mengubah dan menyebarkan informasi di dalam suatu bentuk organisasi”.

Dari pengertian diatas, dapat disimpulkan bahwa sistem informasi adalah kumpulan dari elemen - elemen atau sumber daya dan jaringan yang saling berkaitan satu sama lain membentuk suatu kesatuan untuk mengintegrasi data, dan bertujuan mengolah data menjadi informasi.

\section{Teknologi Informasi}

Teknologi Informasi adalah studi atau peralatan elektronika, terutama komputer, untuk menyimpan, menganalisa, dan mendistribusikan informasi apa saja, termasuk kata-kata, bilangan, dan gambar (kamus Oxford, 1995) .

Menurut Haag \& Keen (1996), "Teknologi Informasi adalah seperangkat alat yang membantu anda bekerja dengan informasi dan melaksanakan tugas-tugas yang berhubungan dengan pemrosesan informasi" .

Menurut martin (1999), “Teknologi Informasi tidak hanya terbatas pada teknologi komputer (software \& hardware) yang digunakan untuk memproses atau menyimpan informasi, melainkan juga mencakup teknologi komunikasi untuk mengirimkan informasi" .

\section{Audit}

Menurut Sukrisno Agoes (2004), "Suatu pemeriksaan yang dilakukan secara kritis dan sistematis oleh pihak yang independen, terhadap laporan keuangan yang telah disusun oleh manajemen beserta catatan- catatan pembukuan dan bukti-bukti pendukungnya, dengan tujuan untuk dapat memberikan pendapat mengenai kewajaran laporan keuangan tersebut" .

Menurut Arens dan Loebbecke (2003), "Suatu proses pengumpulan dan 
pengevaluasian bahan bukti tentang informasi yang dapat diukur mengenai suatu entitas ekonomi yang dilakukan seorang yang kompeten dan independen untuk dapat menentukan dan melaporkan kesesuaian informasi dengan kriteria-kriteria yang telah ditetapkan. Auditing seharusnya dilakukan oleh seorang yang independen dan kompeten" .

Menurut Mulyadi (2002), "Auditing merupakan suatu proses sistematik untuk memperoleh dan mengevaluasi bukti secara objektif mengenai pernyataan-pernyataan tentang kegiatan dan kejadian ekonomi dengan tujuan untuk menetapkan tingkat kesesuaian antara pernyataanpernyataan tersebut dengan criteria yang telah ditetapkan, serta penyampaian hasil-hasilnya kepada pemakai yang berkepentingan" . Dari pengertian diatas, dapat disimpulkan bahwa audit adalah proses pengumpulan dan evaluasi bukti dengan tujuan untuk menentukan dan melaporkan kesesuaian informasi dengan kriteria - kriteria yang telah di tetapkan.

Tujuan audit adalah mendapatkan informasi faktual dan signifikan berupa data hasil analisa, penilaian, rekomendasi auditor yang dapat digunakan oleh auditee atau menejemen untuk berbagai keperluan misalnya untuk dasar pengambilan keputusan , pengendalian manajemen, perbaikan atau perubahan dalam berbagai aspek dalam upaya mengamankan kebijakan dan mencapai tujuan organisasi secara keseluruhan .

\section{Audit Sistem Informasi/Teknologi Informasi}

Menurut Weber (1999, p.10), “Audit sistem informasi adalah proses pengumpulan dan pengevaluasian bukti untuk menentukan apakah sistem komputer dapat melindungi aset, memelihara integritas data, memungkinkan tujuan organisasi untuk dicapai secara efektif dan menggunakan sumber daya secara efisien".

Menurut Gondodiyoto (2003, p.151), "Audit sistem informasi merupakan suatu pengevaluasian untuk mengetahui bagaimana tingkat kesesuaian antara aplikasi sistem informasi dengan prosedur yang telah ditetapkan dan mengetahui apakah suatu sistem informasi telah didesain dan diimplementasikan secara efektif, efisien, dan ekonomis, memiliki mekanisme pengamanan aset yang memadai, serta menjamin integritas data yang memadai" Dari pengertian diatas, dapat disimpulkan bahwa audit sistem informasi adalah proses pengumpulan bukti dan evaluasi untuk mengetahui tingkat kesesuaian sistem informasi dengan prosedur yang telah ditetapkan dan mengetahui apakah sistem informasi telah didesain dan diimplementasikan secara efektif, efisien dan ekonimis, memiliki mekanisme pengamanan asset yang memadai dan menjamin integritas data.

\section{COBIT}

Menurut Sasongko (2009), "Control Objective for Information \& Related Technology(COBIT) adalah sekumpulan dokumentasi best practice untuk IT Governance yang dapat membantu auditor, pengguna (user), dan manajemen, untuk menjembatani gap antara resiko bisnis, kebutuhan kontrol dan masalahmasalah teknis IT".

Menurut Tanuwijaya dan Sarno (2010), “COBIT mendukung tata kelola TI dengan menyediakan kerangka kerja untuk mengatur keselarasan TI dengan 
bisnis. Selain itu, kerangka kerja juga memastikan bahwa TI memungkinkan bisnis, memaksimalkan keuntungan, resiko TI dikelola secara tepat, dan sumber daya TI digunakan secara bertanggung jawab" .

COBIT adalah salah satu framework yang digunakan untuk standar audit, COBIT merupakan standar yang dinilai lengkap dan cakupan yang menyeluruh sebagai framework audit. COBIT dikembangkan secara berkala oleh ISACA. Didalam COBIT ini terdapat beberapa Domain yang digunakan untuk proses audit.

\section{Metodologi}

\section{Metode Konseptual}

Penelitian yang akan dilakukan akan terdiri dari beberapa fase-fase audit yang terdiri dari perencanaan, pengumpulan data, analisis data, dan laporan. Audit akan dijalankan mulai studi pendahuluan terhadap studi pustaka dan studi kasus, kemudian fase terakhir akan diakhiri dengan pembuatan laporan yang didalamnya terdapat hasil rekomendasi, yang menunjukkan kegiatan audit selesai dan ditutup

\section{Implementasi dan Analisis Hasil}

\section{Teknik Pengumpulan Data}

Tahap awal pelaksanaan audit ini adalah pengumpulan data, untuk mendukung penilaian ,evaluasi lapangan dan juga untuk mengetahui kondisi nyata dari Direktorat SISFO terhadap audit yang dilakukan. Pengumpulan data dilakukan melalui kuisioner, wawancara, dan survey lapangan. Dalam pengumpulan data melalui kuisioner dan wawancara ini dilakukan berdasarkan tabel Raci Chart yang sudah dipetakan dengan struktur organisasi di Universitas XYZ.

\section{Kuisioner}

Pada tahap ini, dilakukannya kuisioner untuk mencari tanggapan - tanggapan dari para responden mengenai kondisi terkini yang ada pada Direktorat SISFO terkait dengan domain DSS (Deliver, Service and Support). Kuisioner ini berisikan pertanyaan - pertanyaan yang sesuai dengan proses - proses yang ada pada Domain DSS (Deliver, Service and Support).

\section{Wawancara}

Pada tahap wawancara ini, dilakukan untuk mengkroscek/mencari kebenaran dari tanggapan tanggapan pada kuisioner yang telah di dapat, dan juga untuk memperoleh bukti - bukti yang terkait dengan domain DSS (Deliver, Service and Support). Wawancara dilakukan secara face to face dengan responden, dan juga didokumentasikan dengan rekaman wawancara.

\section{Langkah Pengumpulan Data}

Dalam pengumpulan data terdapat langkah tersendiri, berikut adalah langkah - langkah 
peneliti untuk melakukan pengumpulan data

\section{Kesimplan dan Saran}

\section{Kesimpulan}

Berdasarkan audit yang dilakukan pada Direktorat SISFO Universitas XYZ dalam study kasus dengan framework COBIT 5 Domain DSS (Deliver, Service, and Support) maka kesimpulan dari tugas akhir ini adalah :

1) Pada tahap Pra audit telah diperoleh 6 proses domain DSS COBIT 5 yang dimana merupakan keseluruhan proses dari domain DSS yang sesuai dengan kondisi tata kelola Direktorat SISFO Universitas XYZ dan digunakan sebagai ruang lingkup dan standar audit yaitu DSS01, DSS02, DSS03, DSS04, DSS05, dan DSS06.

2) Dari hasil audit, diketahui ada 1 proses yang mempunyai level kapabilitas 4 yaitu DSS02, ada 5 proses yang mempunyai level kapabilitas 3 yaitu DSS01, DSS03, DSS04, DSS05 dan DSS06.

3) Menurut level kapabilitas masing- masing proses, ditentukan level target masing-masing proses yaitu berupa 1 level di atas level kapabilitas,yang ditentukan berdasar analisis dan juga persetujuan dengan stakeholder, sehingga didapat level target untuk DSS01, DSS03, DSS04, DSS05 dan DSS06 adalah level 4, untuk DSS02 adalah level 5.

4) Level capability keseluruhan yang diperoleh berdasarkan keseluruhan rata rata adalah 3, yang berarti sebagian besar aktifitas pada domain DSS untuk Direktorat SISFO Telkom University telah dilakukan, ada standar penerapan dalam melakukan proses tersebut, terdokumentasi dan komunikasi berjalan dengan baik.

\footnotetext{
Saran

Berikut adalah saran yang dapat disampaikan dalam tugas akhir ini adalah :
}

1) Penilaian tingkat kapabilitas terkait Direktorat SISFO Universitas $X Y Z$ dalam tugas akhir ini dapat dilanjutkan lagi pada modul-modul lain menggunakan COBIT 5.

2) Dapat ditambahkan scoring/pembobotan dalam terkait pengumpulan bukti/evidence yang dicari, Untuk memperjelas pemberian rekomendasi.

3) Metode dalam penghitungan validasi dan penentuan level capability tiap aktifitas dapat dilakukan dengan metode yang berbeda. 